\title{
Exploration in the mechanism of fucosterol for the treatment of non-small cell lung cancer based on network pharmacology and molecular docking
}

\section{Xiaoling Li}

Guangdong Medical University

\section{Baixin Lin}

Guangdong Medical University

\section{Zhiping Lin}

Guangdong Medical University

Qu Wang

Guangdong Medical University

\section{Yushi Zheng}

Guangdong Medical University

Liao Cui

Guangdong Medical University

Hui Luo

Guangdong Medical University

Lianxiang Luo ( $\nabla$ luolianxiang321@163.com )

Guangdong Medical University https://orcid.org/0000-0002-3391-9713

\section{Primary research}

Keywords: Fucosterol, Non-small cell lung cancer, Network pharmacology, Molecular docking, Ingenuity pathway analysis

Posted Date: June 30th, 2020

DOl: https://doi.org/10.21203/rs.3.rs-38065/v1

License: (c) (i) This work is licensed under a Creative Commons Attribution 4.0 International License. Read Full License

Version of Record: A version of this preprint was published at Scientific Reports on March 1st, 2021. See the published version at https://doi.org/10.1038/s41598-021-84380-w. 


\section{Abstract}

\section{Background}

It has been demonstrated that fucosterol induces a therapeutic effect on cancer. However, the molecular mechanisms underlying the effects of fucosterol in the treatment of non-small cell lung cancer are still unclear.

Methods

In this study, pharmMapper and GeneCards databases were utilized to gather the prediction of fucosterol targets and NSCLC-related targets. The mechanisms of fucosterol against NSCLC were identified in DAVID6.8 by enrichment analysis of GO and KEGG, and protein-protein interaction data was obtained from Sting Database. Molecular docking was used to predict the docking of GRB2. Moreover, the relationship of GRB2 expression and immune infiltrates was analyzed by TIMER database.

Results

The results suggest that fucosterol acts against by candidate targets, such as MAPK1, EGFR, GRB2, IGF2, MAPK8 and SRC, which regulate biological processes including negative regulation of apoptotic process, peptidyl-tyrosine phosphorylation, positive regulation of cell proliferation. The Raf / MEK / ERK signaling pathway initiated by GRB2 maybe the most significant pathway for fucosterol to treat NSCLC.

Conclusions

These results show that GRB2 is the key target for fucosterol in the treatment of NSCLC, which laying a theoretical foundation for further research and providing scientific support for the development of new drugs.

\section{Background}

Lung cancer is the leading causes of cancer death worldwide [1]. Non-small cell lung cancer (NSCLC) accounts for about $85 \%$ of lung cancer[2]. At present, the main treatment methods of NSCLC are chemotherapy, surgery, radiotherapy and targeted therapy [3], but the five-year survival rate as low as $18 \%$ and may lead to serious side effects and drug resistance $[4,5]$. Therefore, there is an urgent need to develop effective drugs for the treatment of non-small cell lung cancer.

$25 \%$ of the Earth's total species are consist of marine species. Many of these compounds have special biological activities and chemical structures that can be used as potential medicines for many diseases[6, 7]. Most of these marine plants extracts have been confirmed to be anti-cancer [8,9], antiinflammatory[10, 11], anti-viral [12, 13], etc. Marine medicines derived from marine plant extracts have received more and more attention. Brown algae is a kind of macroalgae in the ocean. Fucosterol is a sort of algal phytosterol in ethanol extract of brown algae, which has been proved to have multiple biological 
activities, including antioxidant[14-16], anti-inflammatory[17-19], anticancer[20], antimicrobial[21], antidepression[22], etc. Previous research have reported fucosterol on anti-cervical cancer[20], anti-

leukemia[23], anti-colorectal cancer[24], etc., but there are few studies on the mechanisms of fucosterol in treating non-small cell lung cancer, and its potential therapeutic targets and related pathways have not been reported in detail.

In the past few years, network pharmacology, as a new discipline based on system biology and multidirection pharmacology, can effectively implement the predictive analysis of drug action mechanisms[25], identify new drug targets[26], and better explain the mechanism of interactions between bioactive molecules and cellular pathways. Molecular docking technology is an advantageous tool for modernization research and can achieve virtual screening of drugs[27]. Reverse molecular docking refers to the docking of a small molecule drug in a group of potential binding cavities of clinically relevant large molecule targets. Through detailed analysis of its binding characteristics, the potential small molecule targets are identified and ranked according to the binding tightness[28, 29].

In this study, network pharmacology and molecular docking were utilized to elucidate the mechanisms of fucosterol treatment of NSCLC, providing new ideas for the treatment of NSCLC and promoting the development of new drugs.

\section{Materials And Methods}

\section{Data preparation}

\section{Fucosterol chemical structure}

The PubChem database(https://pubchem.ncbi.nlm.nih.gov/) was used to retrieve the 3D chemical structure of fucosterol and saved it as "sdf" format which imported into Pymol for minimizing the MM2 energy, and finally reserved as mol2 format.

\section{Prediction of fucosterol targets}

Fucosterol's mol2 format was uploaded to the PharmMappper database (http://www.lilabecust.cn/pharmmapper/) to determine the fucosterol-related predictive targets. Set parameters: Generate Conformers: Yes; Maximum Generated Conformations: 300; Select Target Set: Human Protein Target Only; Number of Reserved Matched Targets: 300 . The results of predictive targets with z-score $>0$ as screening criteria were retained for further study.

\section{Protein name correction}

Fucosterol-related predictive targets were input into UniProtKB database (http://www.uniprot.org/) which was utilized to collect the official symbols with the species limited to "Homo sapiens" by eliminating duplicate and nonstandard targets. 


\section{Prediction of targets of fucosterol for NSCLC treatment}

NSCLC-related targets were gathered from GeneCards database(https://www.genecards.org/) using the phrase "non-small cell lung cancer" as a keyword and the top 500 targets were retained according to the relevance score. The predictive targets of fucosterol were compared with the NSCLC-related targets in BioVenn(http://www.biovenn.nl/index.php) to determine the candidate targets of fucosterol for NSCLC treatment.

\section{Protein-Protein interaction data}

The data on protein-protein interaction (PPI) were obtained from String database (https://string-db.org/) with uploading the candidate targets of fucosterol relevant to the treatment of NSCLC while the species limited to "Homo sapiens" and the confidence score > 0.9 (low confidence: score < 0.400; medium confidence: $0.400<$ score $<0.700$; high confidence: $0.700<$ score $<0.900$; highest confidence: score > 0.900).

\section{Enrichment analysis}

DAVID 6.8 (https://david.ncifcrf.gov/home.jsp) was applied to carry out GO enrichment analysis and KEGG pathway enrichment analysis of the candidate targets. First, the species option was selected as "Homo sapiens". Second, four analysis items were selected: KEGG pathway, cellular components, molecular functions, and biological processes. Third, Enriched GO terms and pathways were screened for P-value $\leq 0.05$ using the Bonferroni correction. Finally, KEGG pathway and the top 20 items of GO with ranking by their P-value based on the third step were chosen for further analysis.

\section{Network construction}

\section{Network construction method}

The Cytoscape3.7.2 software was utilized for network topology analysis and network visualization. Construct the following networks:(1) Cluster 1 for non-small cell lung cancer network; (2) FucosterolNSCLC candidate targets PPI network; (3) important biological processes and candidate targets crosstalk network; (4) KEGG pathway and candidate targets crosstalk network

\section{Cluster for NSCLC network}

The disease module is a set of network components that collectively disrupts cellular function and lead to a specific disease phenotype. Owing to the disease module, the functional module and the topology module have the same meaning in the network, the function module is equal to the topology module, and the disease can be can be considered as interference and destruction of functional module[30, 31].The plug-in MCODE of Cytoscape3.7.2 software was used to analyze the protein interaction network of nonsmall cell lung cancer to find the dense regions, and the first cluster of results was retained. 
The biological processes of candidate targets enrichment analysis retained based on the above-mention steps were compared and screened with the results obtained by NSCLC the first cluster network enrichment analysis. The relationship between the important biological processes and the candidate targets was visualized through a network.

\section{Screening of KEGG pathways}

Results of KEGG enrichment analysis were removed disease and generalized pathways after filtering by the above steps, and the relationship between pathways and the candidate targets was presented by a network.

\section{An Integrated pathway map construction}

For exploring the comprehensive mechanism of fucosterol treatment of NSCLC, an integrated pathway map related to NSCLC was established, including the non-small cell lung cancer pathway and the key signal transduction pathways.

\section{Prediction of binding between fucosterol and GRB2}

In this work, the initial structure of the ligand-free structure of the GRB2(PDB code: 6SDF), was obtained from X-ray diffraction which in Protein Data Bank and the 3D structure of fucosterol was obtained from Pubchem (compound CID: 5281328). Then, we using AutoDock 4 which based on the standard docking procedure for a rigid protein and a flexible ligand. At first we used pymol2.3 to remove the water molecules and the original ligands from the GRB2, and then used AutoDock4 to add hydrogen and use the vina to dock the GRB2 with fucosterol, and then select the compound with the best binding effect. Finally, we use pymol2.3 to observe and analyze the interaction and binding mode between ligand and receptor.

\section{GRB2 expression and immune infiltrates}

In order to explore the correlation between GRB2 expression and immune infiltrates in LUAD, the TIMER database (https://cistrome.shinyapps.io/timer/), a friendly comprehensive tool set for integrated analysis of immune infiltrates across diverse types of cancer, was carried out. There were six immune cells involving in the analysis, including CD $4+T$ cells, CD $8+T$ cells, B cells, neutrophils, macrophages and dendritic cells in the TIMER database. Besides, we performed the association between gene GRB2 and EGFR after adjusting tumor purity.

\section{Prognostic values of GRB2}

The correlation between GRB2 expression and survival in lung adenocarcinoma was analyzed by KaplanMeier plotter (http://kmplot.com/analysis/), a tool for assessing the functions of 54,675 genes and 10,188 tumor tissue samples, including breast cancer, ovarian cancer, lung cancer, and gastric cancer. 


\section{Results}

\section{Prediction of fucosterol related targets}

A diagrammatic overview displaying the different steps of network pharmacology and molecule was illustrated in Fig. 1. We identified 210 predictive targets from the Pharmmapper database, and ultimately, we obtained 135 official symbols of fucosterol related targets for limiting to "Homo sapiens" in the UniProtKB database after filtering by $z$-score $>0$ (Table 1 ). 
Table 1

Prediction targets of fucosterol

\begin{tabular}{|lll|}
\hline Pharma Model & Gene symbol & z-score \\
\hline 3fOr_v & HDAC8 & 2.82743 \\
\hline 1qyx_v & HSD17B1 & 2.70536 \\
\hline 1o6u_v & SEC14L2 & 2.68742 \\
\hline 1n83_v & RORA & 2.39228 \\
\hline 1a28_v & PGR & 2.2175 \\
\hline 1ya3_v & NR3C2 & 2.13319 \\
\hline 1s9j_v & MAP2K1 & 2.12046 \\
\hline 1q22_v & SULT2B1 & 1.98504 \\
\hline 1pic_v & PIK3R1 & 1.88125 \\
\hline 1lv2_v & HNF4G & 1.83771 \\
\hline 1rhr_v & CASP3 & 1.80882 \\
\hline 1osh_v & NR1H4 & 1.79715 \\
\hline 830c_v & MMP13 & 1.78365 \\
\hline 1rbp_v & RBP4 & 1.71609 \\
\hline 1lho_v & SHBG & 1.70322 \\
\hline 1mrq_v & AKR1C1 & 1.70301 \\
\hline 1sz7_v & TRAPPC3 & 1.6669 \\
\hline 3czr_v & HSD11B1 & 1.65102 \\
\hline 2piw_v & AR & 1.6069 \\
\hline 1fd0_v & RARG & 1.59522 \\
\hline 1d4p_v & F2 & 1.55496 \\
\hline 1gse_v & GSTA1 & 1.54788 \\
\hline 1uhl_v & NR1H3 & 1.52908 \\
\hline 1hrk_v & 1.52472 \\
\hline 2iiv_v & 1.50916 \\
\hline 1s0z_v & PaRA & 1.49513 \\
\hline 1dkf_v & \\
\hline
\end{tabular}




\begin{tabular}{|c|c|c|}
\hline Pharma Model & Gene symbol & z-score \\
\hline 2i6b_v & ADK & 1.38413 \\
\hline $101 \mathrm{v} \_v$ & FABP6 & 1.35079 \\
\hline 2shp_v & PRKACA & 1.28799 \\
\hline 2fjm_v & PTPN11 & 1.27676 \\
\hline 2j14_v & PTPN1 & 1.27187 \\
\hline $1 \times 0 n \_v$ & PPARD & 1.2585 \\
\hline 3bbt_v & GRB2 & 1.25573 \\
\hline 118j_v & ERBB4 & 1.23987 \\
\hline $2 v x 0 \_v$ & PROCR & 1.23974 \\
\hline 1he3_v & EPHB4 & 1.19363 \\
\hline 1pq2_v & BLVRB & 1.19205 \\
\hline 1j99_v & CYP2C8 & 1.08311 \\
\hline 1cbs_v & SULT2A1 & 1.06101 \\
\hline 1sm2_v & CRABP2 & 1.04514 \\
\hline 1upw_v & ITK & 1.03078 \\
\hline 1qpd_v & $\mathrm{NR} 1 \mathrm{H} 2$ & 1.00159 \\
\hline 1 uym_v & LCK & 0.997933 \\
\hline 1hov_v & HSP90AB1 & 0.978531 \\
\hline 1h9u_v & MMP2 & 0.976261 \\
\hline 1u59_v & RXRB & 0.97084 \\
\hline 1fe3_v & ZAP70 & 0.963876 \\
\hline 19gs_v & FABP7 & 0.95545 \\
\hline 2hzi_v & GSTP1 & 0.954306 \\
\hline 1w6k_v & ABL1 & 0.954084 \\
\hline 1yvj_v & LSS & 0.922657 \\
\hline 1 m48_v & JAK3 & 0.917557 \\
\hline 1t84_v & IL2 & 0.909365 \\
\hline 1dxo_v & WAS & 0.886825 \\
\hline
\end{tabular}




\begin{tabular}{|lll|}
\hline Pharma Model & Gene symbol & z-score \\
\hline 1j78_v & NQO1 & 0.867991 \\
\hline 2p4i_v & GC & 0.803103 \\
\hline 1iz2_v & TEK & 0.79593 \\
\hline 1oiz_v & SERPINA1 & 0.795317 \\
\hline 1ln3_v & TTPA & 0.794336 \\
\hline 1t4e_v & PCTP & 0.78729 \\
\hline 1xap_v & MDM2 & 0.775562 \\
\hline 1qkt_v & RARB & 0.767258 \\
\hline 1r9o_v & ESR1 & 0.742597 \\
\hline 1qip_v & CYP2C9 & 0.733894 \\
\hline 1hmt_v & GLO1 & 0.731703 \\
\hline 1bl6_v & FABP3 & 0.730803 \\
\hline 2rfn_v & MAPK14 & 0.721237 \\
\hline 1i7g_v & MET & 0.707586 \\
\hline 1pmn_v & PPARA & 0.678619 \\
\hline 1e7a_v & MAPK10 & 0.644744 \\
\hline 2oi0_v & ALB & 0.634049 \\
\hline 1cg6_v & ADAM17 & 0.623444 \\
\hline 1ma0_v & MTAP & 0.608206 \\
\hline 1g3m_v & ADH5 & 0.594411 \\
\hline 1xjd_v & SULT1E1 & 0.557908 \\
\hline 2uwd_v & PRKCQ & 0.555214 \\
\hline 1oj9_v & HSP90AA1 & 0.540688 \\
\hline 1njs_v & MAOB & 0.529254 \\
\hline 1xvp_v & NRjl_v & 0.502645 \\
\hline 1nhz_v & NR6_v & \\
\hline
\end{tabular}




\begin{tabular}{|lll|}
\hline Pharma Model & Gene symbol & z-score \\
\hline 2ipw_v & AKR1C2 & 0.434142 \\
\hline 1p49_v & AKR1B1 & 0.426598 \\
\hline 1xbb_v & STS & 0.421996 \\
\hline 1okl_v & SYK & 0.418201 \\
\hline 2qu2_v & CA2 & 0.398063 \\
\hline 1ih0_v & BACE1 & 0.394868 \\
\hline 1sa4_v & TNNC1 & 0.387846 \\
\hline 1l6I_v & FNTA & 0.385162 \\
\hline 2fgi_v & APOA2 & 0.36325 \\
\hline 2pe0_v & FGFR1 & 0.355588 \\
\hline 3hvc_v & PDPK1 & 0.353361 \\
\hline 2h8h_v & SRC & 0.34725 \\
\hline 2itp_v & EGFR & 0.342717 \\
\hline 1xor_v & PDE4D & 0.333997 \\
\hline 1jqe_v & HNMT & 0.312737 \\
\hline 1shj_v & CASP7 & 0.309471 \\
\hline 2iku_v & REN & 0.285831 \\
\hline 2pg2_v & KIF11 & 0.27567 \\
\hline 3bgp_v & PIM1 & 0.259029 \\
\hline 2ywp_v & CHEK1 & 0.245709 \\
\hline 1t46_v & KIT & 0.241973 \\
\hline 1s95_v & PPP5C & 0.227167 \\
\hline 1itu_v & DPEP1 & 0.226319 \\
\hline 2b53_v & CDK2 & 0.222033 \\
\hline 2jbp_v & ACADM & 0.216487 \\
\hline 3cjg_v & Tegc_v & \\
\hline
\end{tabular}

Page 10/30 


\begin{tabular}{|lll|}
\hline Pharma Model & Gene symbol & z-score \\
\hline 1so2_v & PDE3B & 0.191704 \\
\hline 1I9n_v & TGM3 & 0.19101 \\
\hline 2bxr_v & MAOA & 0.187567 \\
\hline 1hw8_v & HMGCR & 0.158181 \\
\hline 1tt6_v & TTR & 0.155605 \\
\hline 2o9i_v & NR1I2 & 0.148658 \\
\hline 1×89_v & LCN2 & 0.147746 \\
\hline 1j4i_v & FKBP1A & 0.145396 \\
\hline 1xlz_v & PDE4B & 0.141599 \\
\hline 1s8c_v & HMOX1 & 0.137498 \\
\hline 1tjj_v & GM2A & 0.121157 \\
\hline 1 mx1_v & CES1 & 0.098769 \\
\hline 2g01_v & MAPK8 & 0.092468 \\
\hline 1reu_v & BMP2 & 0.090768 \\
\hline 1fzv_v & PGF & 0.088164 \\
\hline 1s1p_v & AKR1C3 & 0.08785 \\
\hline 1r7y_v & ABO & 0.071475 \\
\hline 1pme_v & MAPK1 & 0.068987 \\
\hline 1g4k_v & MMP3 & 0.067658 \\
\hline 1h6g_v & CTNNA1 & 0.067305 \\
\hline 1vj5_v & EPHX2 & 0.059538 \\
\hline 2nn7_v & CA1 & 0.049744 \\
\hline 2pin_v & THRB & 0.011683 \\
\hline 1gzr_v & IGF1 & 0.0063 \\
\hline
\end{tabular}

\section{Cluster analysis of NSCLC network}

Although we selected high-relevance score of NSCLC targets from GeneCards, the NSCLC bio-network is still huge. In order to further analyze biological processes of the function module in NSCLC network, we obtained protein-protein interaction network (PPI) data for NSCLC from the String database, and 
Cytoscape3.7.2 plug-in MCODE was used for clustering to find out the topology module of NSCLC's PPI network. The cluster 1 was retained since it is the most significant for PPI network of NSCLC (Fig. 2). We imported the data of cluster 1 into the DAVID6.8 to discover its GO biological processes which were shown in a bubble chart (Fig. 3). Cluster 1 is mainly involved in cell proliferation, apoptosis, cell cycle, angiogenesis, NSCLC gene expression, invasion and migration, signal transduction, and NSCLC related signaling pathways.

\section{Analysis of fucosterol-NSCLC PPI network}

In order to construct the interaction network between proteins and dig out the core regulatory genes, fucosterol-NSCLC PPI network of candidate targets was constructed by Cytoscape3.7.2 based on the String database (Fig. 4). Fucosterol shares 37 targets with NSCLC, and the network consists of 36 nodes (one of which does not interact with other target proteins) and 177 edges. The color of each node is related to its degree; the darker nodes have the larger value of Degree. The size of the node is linked to its Edge; the bigger nodes have the larger value of Edge Between. Based on the network topology analysis, which business centrality is 0.0261 , average node degree is 9.83 , average closeness centrality is 0.535 , which suggests the presence of a central hub between candidate targets. Cytoscape3.7.2 plug-in cytoHubba was utilized to obtain six hub genes, which between centrality, node degree and closeness centrality as screening conditions. We speculate that these hub genes play a significant role in NSCLC treated fucosterol: EGFR, MAPK8, MAPK1, GRB2, SRC, IGF1 (Table 2).

Table 2

Hub genes of fucosterol against NSCLC

\begin{tabular}{|llll|}
\hline Name & Betweenness Centrality & Closeness Centrality & Degree \\
\hline GRB2 & 0.03441407 & 0.614035 & 16 \\
\hline EGFR & 0.06936033 & 0.648148 & 19 \\
\hline MAPK1 & 0.12911792 & 0.729167 & 22 \\
\hline SRC & 0.03183796 & 0.660377 & 18 \\
\hline IGF1 & 0.09323304 & 0.660377 & 18 \\
\hline MAPK8 & 0.18473443 & 0.7 & 20 \\
\hline
\end{tabular}

\section{Gene ontology analysis of candidate targets}

$\mathrm{GO}$ enrichment allows a better understand of the gene function and biological significance of the candidate targets of fucosterol for NSCLC treatment on a systematic level. To obtain the biological processes, molecular functions, and cellular components of the candidate targets, we performed a GO enrichment analysis which was displayed the top 20 significantly terms(p-value $\leq 0.05$ ) of each module in Fig. 5. It is suggested that the candidate targets could act through protein tyrosine kinase activity, protein phosphatase binding, negative regulation of apoptotic process, peptidyl-tyrosine phosphorylation, 
positive regulation of cell proliferation in the nucleus, cytosol, extracellular space, nucleoplasm, extracellular region. Among them, 14 vital biological processes directly affecting the most significant cluster 1 of NSCLC disease module were presented with candidate targets independently (Fig. 6). This network diagram reveals candidate targets were mainly involved in cell proliferation and apoptosis, angiogenesis, cell migration and signal transduction, meanwhile it illustrates that hub genes were strongly associated with various biological processes.

\section{Evaluation of target-pathway network}

As showed in Table 3, 37 candidate targets were further mapped to 73 pathways for more intuitive explain the mechanism of fucosterol in treating NSCLC at the pathway level. Cytoscape3.7.2 was utilized to construct the T-P network which showed the relationship between 37 candidate targets and the pathways that getting rid of generalized and disease terms (Fig. 7). It is found that some targets are mapped to multiple pathways and multiple targets also regulated various pathways, which suggest that candidate targets may mediate interaction and crosstalk of different pathways. These pathways may be the major factor for fucosterol's resistance to non-small cell lung cancer, such as PI3K-Akt signaling pathway, VEGF signaling pathway, ErbB signaling pathway. The PI3K-Akt signaling pathway is widely recognized as a prominent cancer signaling pathway, which is closely related to affect the proliferation, survival and apoptosis of NSCLC cells[32-34]. Also, VEGF signaling pathway involves in tumor celldependent continuous vascular supply, which has a profound effect on tumor cell growth and metastasis[35]. In addition, for interaction of ErbB receptors with many signal transduction molecules which can activate multiple intracellular pathways, the ErbB signaling pathway plays a significant role in the development of cancer[36]. According to T-P network analysis, we discover fucosterol maybe to regulate NSCLC therapy through PI3K-Akt signaling pathway, VEGF signaling pathway, ErbB signaling pathway by apoptosis, tumor angiogenesis, and cell cycle arrest. 
Table 3

KEGG analysis of candidate targets of fucosterol against NSCLC

\begin{tabular}{|c|c|c|c|}
\hline Term & Pathways & Count & PValue \\
\hline hsa05200 & Pathways in cancer & 21 & $1.21 \mathrm{E}-16$ \\
\hline hsa05205 & Proteoglycans in cancer & 17 & 3.47E-16 \\
\hline hsa04151 & PI3K-Akt signaling pathway & 15 & 4.36E-10 \\
\hline hsa04014 & Ras signaling pathway & 13 & $5.06 \mathrm{E}-10$ \\
\hline hsa05215 & Prostate cancer & 11 & 9.84E-12 \\
\hline hsa04015 & Rap1 signaling pathway & 11 & $5.35 \mathrm{E}-08$ \\
\hline hsa04068 & FoxO signaling pathway & 10 & $1.42 \mathrm{E}-08$ \\
\hline hsa04510 & Focal adhesion & 10 & $5.84 \mathrm{E}-07$ \\
\hline hsa04914 & Progesterone-mediated oocyte maturation & 9 & $8.41 \mathrm{E}-09$ \\
\hline hsa04012 & ErbB signaling pathway & 9 & $8.41 \mathrm{E}-09$ \\
\hline hsa04915 & Estrogen signaling pathway & 9 & 2.36E-08 \\
\hline hsa04550 & Signaling pathways regulating pluripotency of stem cells & 9 & 3.57E-07 \\
\hline hsa05203 & Viral carcinogenesis & 9 & $6.39 \mathrm{E}-06$ \\
\hline hsa05218 & Melanoma & 8 & 4.93E-08 \\
\hline hsa04917 & Prolactin signaling pathway & 8 & 4.93E-08 \\
\hline hsa04912 & GnRH signaling pathway & 8 & 2.79E-07 \\
\hline hsa04722 & Neurotrophin signaling pathway & 8 & $1.85 \mathrm{E}-06$ \\
\hline hsa05161 & Hepatitis B & 8 & $6.56 \mathrm{E}-06$ \\
\hline hsa04010 & MAPK signaling pathway & 8 & 2.33E-04 \\
\hline hsa05206 & MicroRNAs in cancer & 8 & $4.92 \mathrm{E}-04$ \\
\hline hsa05230 & Central carbon metabolism in cancer & 7 & $6.71 \mathrm{E}-07$ \\
\hline hsa05214 & Glioma & 7 & 7.37E-07 \\
\hline hsa05120 & Epithelial cell signaling in Helicobacter pylori infection & 7 & 8.84E-07 \\
\hline hsa05220 & Chronic myeloid leukemia & 7 & $1.36 \mathrm{E}-06$ \\
\hline hsa04668 & TNF signaling pathway & 7 & $1.38 \mathrm{E}-05$ \\
\hline hsa05219 & Bladder cancer & 6 & $1.66 \mathrm{E}-06$ \\
\hline hsa05223 & Non-small cell lung cancer & 6 & 8.03E-06 \\
\hline
\end{tabular}




\begin{tabular}{|c|c|c|c|}
\hline Term & Pathways & Count & PValue \\
\hline hsa05221 & Acute myeloid leukemia & 6 & 8.03E-06 \\
\hline hsa04370 & VEGF signaling pathway & 6 & $1.23 \mathrm{E}-05$ \\
\hline hsa05211 & Renal cell carcinoma & 6 & $1.81 \mathrm{E}-05$ \\
\hline hsa04664 & Fc epsilon RI signaling pathway & 6 & $2.10 \mathrm{E}-05$ \\
\hline hsa04066 & HIF-1 signaling pathway & 6 & 1.11E-04 \\
\hline hsa04660 & T cell receptor signaling pathway & 6 & 1.35E-04 \\
\hline hsa05231 & Choline metabolism in cancer & 6 & $1.41 \mathrm{E}-04$ \\
\hline hsa04114 & Oocyte meiosis & 6 & $2.21 \mathrm{E}-04$ \\
\hline hsa04919 & Thyroid hormone signaling pathway & 6 & $2.60 \mathrm{E}-04$ \\
\hline hsa04650 & Natural killer cell mediated cytotoxicity & 6 & 3.43E-04 \\
\hline hsa05169 & Epstein-Barr virus infection & 6 & 3.43E-04 \\
\hline hsa04380 & Osteoclast differentiation & 6 & 4.76E-04 \\
\hline hsa05160 & Hepatitis C & 6 & 5.10E-04 \\
\hline hsa04062 & Chemokine signaling pathway & 6 & 2.30E-03 \\
\hline hsa04810 & Regulation of actin cytoskeleton & 6 & 3.89E-03 \\
\hline hsa05213 & Endometrial cancer & 5 & $1.28 \mathrm{E}-04$ \\
\hline hsa05210 & Colorectal cancer & 5 & $2.54 \mathrm{E}-04$ \\
\hline hsa05131 & Shigellosis & 5 & 2.87E-04 \\
\hline hsa05212 & Pancreatic cancer & 5 & 3.05E-04 \\
\hline hsa04115 & p53 signaling pathway & 5 & 3.43E-04 \\
\hline hsa04520 & Adherens junction & 5 & 4.29E-04 \\
\hline hsa04540 & Gap junction & 5 & 9.67E-04 \\
\hline hsa04750 & Inflammatory mediator regulation of TRP channels & 5 & $1.45 \mathrm{E}-03$ \\
\hline hsa05142 & Chagas disease (American trypanosomiasis) & 5 & $1.80 \mathrm{E}-03$ \\
\hline hsa04620 & Toll-like receptor signaling pathway & 5 & $1.93 \mathrm{E}-03$ \\
\hline hsa04071 & Sphingolipid signaling pathway & 5 & $3.04 \mathrm{E}-03$ \\
\hline hsa04910 & Insulin signaling pathway & 5 & 5.01E-03 \\
\hline hsa04630 & Jak-STAT signaling pathway & 5 & 5.97E-03 \\
\hline
\end{tabular}




\begin{tabular}{|llll|}
\hline Term & Pathways & Count & PValue \\
\hline hsa05202 & Transcriptional misregulation in cancer & 5 & $9.76 \mathrm{E}-03$ \\
\hline hsa05164 & Influenza A & 5 & $1.12 \mathrm{E}-02$ \\
\hline hsa05152 & Tuberculosis & 4 & $1.19 \mathrm{E}-02$ \\
\hline hsa04320 & Dorso-ventral axis formation & 4 & $3.25 \mathrm{E}-04$ \\
\hline hsa04621 & NOD-like receptor signaling pathway & 4 & $5.78 \mathrm{E}-03$ \\
\hline hsa04662 & B cell receptor signaling pathway & 4 & $6.34 \mathrm{E}-03$ \\
\hline hsa05133 & Pertussis & 4 & $1.80 \mathrm{E}-02$ \\
\hline hsa05145 & Toxoplasmosis & 4 & $2.02 \mathrm{E}-02$ \\
\hline hsa04670 & Leukocyte transendothelial migration & 4 & $2.46 \mathrm{E}-02$ \\
\hline hsa04110 & Cell cycle & 4 & $2.78 \mathrm{E}-02$ \\
\hline hsa04611 & Platelet activation & 4 & $2.95 \mathrm{E}-02$ \\
\hline hsa05162 & Measles & 4 & $4.00 \mathrm{E}-02$ \\
\hline hsa04921 & Oxytocin signaling pathway & 3 & $1.66 \mathrm{E}-02$ \\
\hline hsa04960 & Aldosterone-regulated sodium reabsorption & 3 & $2.45 \mathrm{E}-02$ \\
\hline hsa04930 & Type ll diabetes mellitus & 3 & $3.48 \mathrm{E}-02$ \\
\hline hsa04150 & mTOR signaling pathway & 3 & $3.70 \mathrm{E}-02$ \\
\hline hsa04730 & Long-term depression & 4 & \\
\hline
\end{tabular}

\section{Analysis of an Integrated pathway map}

To further explicate the complex mechanism of fucosterol in the treatment of NSCLC, an integrated pathway map (Fig. 8) was constructed by integrating the non-small cell lung cancer disease pathway map and the key signal transduction pathways map that obtained from evaluating of T-P network. The key signal transduction pathways map comprises of three signaling pathways: hsa04151: PI3K-Akt signaling pathway, hsa04012: ErbB signaling pathway, hsa04370: VEGF signaling pathway. As shown in Fig. 8, the signaling transduction pathways and NSCLC disease pathway reflect multiple modules such as cell proliferation, apoptosis, migration and angiogenesis. From the perspective of non-small cell lung cancer disease pathway (Fig. 8A), it was found that the fucosterol treatment of NSCLC can crosstalk the inflammatory module and the tumor module, involving the joint action of multiple pathways. Fucosterol can directly activate the Ras signaling pathway, PI3K-Akt signaling pathway, and ErbB signaling pathway, and indirectly activate the MAPK signaling pathway to regulate cell proliferation and apoptosis to achieve the therapeutic effect on NSCLC. From the perspective of the key signal transduction pathways(Fig. 8B), it was found that both VEGF signaling pathway and ErbB signaling pathway can activate downstream 
signals to control angiogenesis, affect cell proliferation and migration, and play a crucial role in the development and metastasis of tumors[37-39]. Meanwhile, the PI3K-Akt signaling pathway participates in the regulation of cell cycle progression[40-42]. According to this map, we found the three signaling pathways can jointly activate the Raf / MEK / ERK signaling pathway which was reported playing an antiproliferation role in curing cancer[43]. More importantly, the downstream pathway-Raf / MEK / ERK signaling pathway mainly activated by GRB2 to regulate cell proliferation and migration. We will further discuss GRB2 which is a significant target in fucosterol for treating NSCLC.

\section{The expression of GRB2 and immune infiltrates in NSCLC}

The docking mode and hydrogen bonding residues of fucosterol with GRB2 after docking are shown in Fig. 9. Then,the binding sites of ligands and GRB2 and the surrounding residues are shown by pymol in Fig. 9A. In the docking model of fucosterol and GRB2, the action site are ASP-16, LYS-11,LYS-21,Ser33,ASN-30, which forms hydrogen bonds with Ser-33, while the interaction between ligands and surrounding residues is analyzed in Fig. 9B. It was able to be seen that the connection between ligands and GRB2 mainly depends on hydrophobic interaction, only Ser-33 forms hydrogen bonds, and the binding energy is- $9.9 \mathrm{kcal} / \mathrm{mol}$, indicating that the binding effect between them is still decent. Besides, we conducted the TIMER database to analyze the relationship GRB2 expression and immune infiltrates. As shown in Fig. 10A-B, the expression of GRB2 was significantly negatively associated with tumor purity while significantly positively correlated with infiltrating levels of immune cells, CD $4^{+} T$ cells $(r=0.385729$ $P=1.28 \mathrm{e}-18), C^{+}{ }^{+} T$ cells $(r=00.307506, P=3.99 \mathrm{e}-12)$, $B$ cells $(r=-0.196239, P=1.37 e-05)$, neutrophils $(r$ $=0.541071, P=4.43 e-38)$, macrophages $(r=0.404903, P=1.47 e-20)$ and dendritic cells $(r=0.544328, P=$ $5.45 \mathrm{e}-39$ ), suggesting that the GRB2 expression was mainly related to the immune infiltration of $\mathrm{CD} 4^{+} T$ cells, $C D 8^{+} T$ cells, $B$ cells, neutrophils, macrophages and dendritic cells. Besides, the result in KM plotter showed that the lower expression level of GRB2 has a better overall survival rate and gene GRB2 was an independent prognosis indicator for OS of patients with LUAD( Fig. 10C-D). Hence, we speculated that GRB2 exerted a more significant effect on the prognosis of LUAD, for it was highly associated with various immune cells in LUAD.

\section{Discussion}

Non-small cell lung cancer is characterized by high malignancy, low 5-year survival rate and poor prognosis. However, for patients with advanced lung cancer, having specific predictive biomarkers and receiving targeted therapy or immunotherapy significantly improves quality of life and progression-free survival (PFS) compared to chemotherapy[44-49]. Hence, finding effective targeted drugs to anti-lung cancer has become an urgent problem to be solved. Network pharmacology can analyze and explain the complexity between biological systems, diseases, and drugs from a network perspective, becoming a frontier method of drug discovery[50,51]. Therefore, the research on the mechanism of fucosterol in the treatment of NSCLC based on network pharmacology may serve as the foundation for the development of targeted drugs for NSCLC in the future. 
Based on the reverse of molecular docking technology for predicting fucosterol targets, and compare with NSCLC disease targets, we obtained 37 candidate targets. Fucosterol-NSCLC PPI network analysis uncovered that fucosterol probably exerted pharmacological effects on NSCLC via 37 candidate targets which including 6 hub genes: GRB2, EGFR, MAPK1, SRC, IGF2, MAPK8. According to GO biological process analysis, 37 candidate targets were found to mainly responsible for cell proliferation, apoptosis, migration, signal transduction and angiogenesis. Meanwhile, KEGG analysis of candidate targets disclosed that fucosterol has an effective effect on the treatment of NSCLC mainly via multiple modules such as cell proliferation, apoptosis, migration and angiogenesis. Through the integrated pathway map, we discover that the Raf / MEK / ERK pathway that GRB2 can participate as a trigger or initiating signal is critical to the treatment of NSCLC.

Growth factor receptor-bound protein 2 (Grb2) is a universally expressed adaptor protein that can play a pivotal downstream mediator role in a variety of oncogenes signaling pathways and has a significant effect on signal transduction in normal and cancer cells[52,53]. Grb2 is a downstream protein of epidermal growth factor receptor (EGFR) that is known to be closely related to NSCLC, and may serve as an adaptor protein to bind to phosphorylated tyrosine in the EGFR known to be closely associated with NSCLC, thereby linking receptor activation to intracellular signaling cascade[54-56]. Recently, research has shown that the balance of Grb2 monomer-dimer is a determinant of its normal and carcinogenic functions[57]. Grb2, which regulates angiogenesis and cell movement, is highly overexpressed in tumors and may be useful as a target for anticancer agents. In the present study, we found Grb2 can be targeted by fucosterol, and activate the Raf / MEK / ERK pathway to achieve the purpose for treating NSCLC[43, 58-60].

In summary, our study indicated the molecular and pharmacological mechanism of fucosterol against NSCLC from a systematic perspective. We unveiled GRB2, as an anticancer target in fucosterol, to initiate the Raf / MEK / ERK pathway for treating non-small cell lung cancer. And, this strategy provides a new idea of anti-NSCLC and lays a foundation for the development of new medicines. Nonetheless, network pharmacology has certain limitations, and more experiments are needed to verify the validity of our findings. Moreover, we hope that our study will be useful for fostering innovative research of marine drugs against cancers.

\section{Abbreviations}

NSCLC Non-small cell lung cancer

GRB2 Growth factor receptor-binding protein 2

KEGG Kyoto Encyclopedia of Gene and Genome

GO Gene Ontology

PPI Protein-protein interaction 


\section{Declarations}

\section{Consent for publication}

Not applicable.

\section{Competing interests}

The authors declare that they have no competing interests.

\section{Ethics approval and consent to participate}

Not applicable.

\section{Availability of data and materials}

The data that support the findings of this study are available from the corresponding author upon reasonable request.

\section{Funding}

This project was supported by the PhD Start-up Fund of Guangdong Medical University (B2019016); Administration of Traditional Chinese Medicine of Guangdong Province (20201180); Science and Technology Special Project of Zhanjiang (2019A01009); Natural Science Foundation of Guangdong Province (2016B030309002); Basic and Applied Basic Research Program of Guangdong Province (2019A1515110201); GDNRC[2020]038; Educational Commission of Guangdong Province (4SG20138G)

\section{Author contributions}

LX Luo conceived the idea; XL Li, YS Zheng, ZP Lin, BX Lin, Q Wang contributed to the acquisition, analysis, and interpretation of data. LX Luo and BX Lin wrote the manuscript; H Luo, L Cui, and LX Luo reviewed the paper and provided comments, and all authors reviewed the manuscript.

\section{Acknowledgements}

Not applicable. 
1. Lin YJ, Liang WM, Chen CJ, Tsang H, Chiou JS, Liu X, Cheng CF, Lin TH, Liao CC, Huang SM, Chen J, Tsai FJ, Li TM. Network analysis and mechanisms of action of Chinese herb-related natural compounds in lung cancer cells. Phytomedicine. 2019;58:152893.

2. Herbst RS, Morgensztern D, Boshoff $C$. The biology and management of non-small cell lung cancer. Nature. 2018;553(7689):446-54.

3. Keith RL, Miller YE. Lung cancer chemoprevention: current status and future prospects. Nature Reviews Clinical Oncology. 2013;10(6):334-43.

4. Siegel RL, Miller KD, Jemal A. Cancer statistics, 2015. CA Cancer J Clin. 2015;65(1):5-29.

5. Ho MM, Ng AV, Lam S, Hung JY. Side Population in Human Lung Cancer Cell Lines and Tumors Is Enriched With Stem-Like. Cancer Cells Cancer Research. 2007;67:4827-33.

6. Mora C, Tittensor DP, Adl S, Simpson AG, Worm B. How many species are there on Earth and in the ocean? PLoS Biol. 2011;9(8):e1001127.

7. Jaspars $M$, De Pascale $D$, Andersen JH, Reyes F, Crawford AD, lanora A. The marine biodiscovery pipeline and ocean medicines of tomorrow. Journal of the Marine Biological Association of the United Kingdom. 2016;96(1):151-8.

8. Mehra R, Bhushan S, Bast F, Singh S. Marine macroalga Caulerpa: role of its metabolites in modulating cancer signaling. Mol Biol Rep. 2019;46(3):3545-55.

9. Khalifa SAM, Elias N, Farag MA, Chen L, Saeed A, Hegazy MF, Moustafa MS, Abd El-Wahed A, AlMousawi SM, Musharraf SG, Chang FR, Iwasaki A, Suenaga K, Alajlani M, Goransson U, El-Seedi HR. Marine Natural Products: A Source of Novel Anticancer Drugs. Mar Drugs 2019;17(9).

10. Fernando IPS, Nah JW, Jeon YJ. Potential anti-inflammatory natural products from marine algae. Environ Toxicol Pharmacol. 2016;48:22-30.

11. Vasarri M, Leri M, Barletta E, Ramazzotti M, Marzocchini R, Degl'Innocenti D. Anti-inflammatory properties of the marine plant Posidonia oceanica (L.) Delile. J Ethnopharmacol. 2020;247:112252.

12. Luthuli S, Wu S, Cheng Y, Zheng X, Wu M, Tong H. Therapeutic Effects of Fucoidan: A Review on Recent Studies. Mar Drugs 2019;17(9).

13. Qureshi D, Nayak SK, Maji S, Kim D, Banerjee I, Pal K. Carrageenan: A Wonder Polymer from Marine Algae for Potential Drug Delivery Applications. Curr Pharm Des. 2019;25(11):1172-86.

14. Lee S, Lee YS, Jung SH, Kang SS, Shin KH. Anti-oxidant Activities of Fucosterol From the Marine Algae Pelvetia Siliquosa. Arch Pharmacal Res. 2003;26:719-22.

15. Choi JS, Han YR, Byeon JS, Choung SY, Sohn HS, Jung HA. Protective effect of fucosterol isolated from the edible brown algae, Ecklonia stolonifera and Eisenia bicyclis, on tert-butyl hydroperoxideand tacrine-induced HepG2 cell injury. J Pharm Pharmacol. 2015;67(8):1170-8.

16. Fernando IPS, Jayawardena TU, Kim HS, Lee WW, Vaas A, De Silva HIC, Abayaweera GS, Nanayakkara CM, Abeytunga DTU, Lee DS, Jeon YJ. Beijing urban particulate matter-induced injury and inflammation in human lung epithelial cells and the protective effects of fucosterol from Sargassum binderi (Sonder ex J. Agardh). Environ Res. 2019;172:150-8. 
17. Sun Z, Mohamed MAA, Park SY, Yi TH. Fucosterol protects cobalt chloride induced inflammation by the inhibition of hypoxia-inducible factor through PI3K/Akt pathway. Int Immunopharmacol. 2015;29(2):642-7.

18. Li Y, Li X, Liu G, Sun R, Wang L, Wang J, Wang H. Fucosterol attenuates lipopolysaccharide-induced acute lung injury in mice. J Surg Res. 2015;195(2):515-21.

19. Andrade PB, Barbosa M, Matos RP, Lopes G, Vinholes J, Mouga T, Valentao P. Valuable compounds in macroalgae extracts. Food Chem. 2013;138(2-3):1819-28.

20. Jiang H, Li J, Chen A, Li Y, Xia M, Guo P, Yao S, Chen S. Fucosterol exhibits selective antitumor anticancer activity against HeLa human cervical cell line by inducing mitochondrial mediated apoptosis, cell cycle migration inhibition and downregulation of m-TOR/PI3K/Akt signalling pathway. Oncol Lett. 2018;15(3):3458-63.

21. Santos SAO, Trindade SS, Oliveira CSD, Parreira P, Rosa D, Duarte MF, Ferreira I, Cruz MT, Rego AM, Abreu MH, Rocha SM, Silvestre AJD. Lipophilic Fraction of Cultivated Bifurcaria bifurcata R. Ross: Detailed Composition and In Vitro Prospection of Current Challenging Bioactive Properties. Mar Drugs 2017;15(11).

22. Zhen XH, Quan YC, Jiang HY, Wen ZS, Qu YL, Guan LP. Fucosterol, a sterol extracted from Sargassum fusiforme, shows antidepressant and anticonvulsant effects. Eur J Pharmacol. 2015;768:131-8.

23. Ji YB, Ji CF, Yue L. Study on human promyelocytic leukemia HL-60 cells apoptosis induced by fucosterol. Biomed Mater Eng. 2014;24(1):845-51.

24. Ramos AA, Almeida T, Lima B, Rocha E. Cytotoxic activity of the seaweed compound fucosterol, alone and in combination with 5-fluorouracil, in colon cells using 2D and 3D culturing. J Toxicol Environ Health A. 2019;82(9):537-49.

25. Iorio F, Bosotti R, Scacheri E, Belcastro V, Mithbaokar P, Ferriero R, Murino L, Tagliaferri R, BrunettiPierri N, Isacchi A, Bernardo Dd. Discovery of Drug Mode of Action Drug Repositioning From Transcriptional Responses PNAS. 2010;107:14621-6.

26. Zhang M, Su S, Bhatnagar RK, Hassett DJ, Lu LJ. Prediction and analysis of the protein interactome in Pseudomonas aeruginosa to enable network-based drug target selection. PLoS One. 2012;7(7):e41202.

27. Pinzi L, Rastelli G. Molecular Docking: Shifting Paradigms in Drug Discovery. Int J Mol Sci 2019;20(18).

28. Duan C, Li Y, Dong X, Xu W, Ma Y. Network Pharmacology and Reverse Molecular Docking-Based Prediction of the Molecular Targets and Pathways for Avicularin Against Cancer. Comb Chem High Throughput Screen. 2019;22(1):4-12.

29. Chen F, Wang Z, Wang C, Xu Q, Liang J, Xu X, Yang J, Wang C, Jiang T, Yu R. Application of reverse docking for target prediction of marine compounds with anti-tumor activity. J Mol Graph Model. 2017;77:372-7.

30. Bader GD, Hogue CWV. An Automated Method for Finding Molecular Complexes in Large Protein Interaction Networks BMC Bioinformatics 2003;4. 
31. Yang K, Zeng L, Ge A, Chen Z, Bao T, Long Z, Ge J, Huang L. Investigating the regulation mechanism of baicalin on triple negative breast cancer's biological network by a systematic biological strategy. Biomed Pharmacother. 2019;118:109253.

32. Zhou B, Wang D, Sun G, Mei F, Cui Y, Xu H. Effect of miR-21 on Apoptosis in Lung Cancer Cell Through Inhibiting the PI3K/ Akt/NF-kappaB Signaling Pathway in Vitro and in Vivo. Cell Physiol Biochem. 2018;46(3):999-1008.

33. Fumarola C, Bonelli MA, Petronini PG, Alfieri RR. Targeting PI3K/AKT/mTOR pathway in non small cell lung cancer. Biochem Pharmacol. 2014;90(3):197-207.

34. Jiang J, Xu Y, Ren H, Wudu M, Wang Q, Song X, Su H, Jiang X, Jiang L, Qiu X. MKRN2 inhibits migration and invasion of non-small-cell lung cancer by negatively regulating the PI3K/Akt pathway. J Exp Clin Cancer Res. 2018;37(1):189.

35. Li X, Wang $X, Y e H$, Peng A, Chen L. Barbigerone, an isoflavone, inhibits tumor angiogenesis and human non-small-cell lung cancer xenografts growth through VEGFR2 signaling pathways. Cancer Chemother Pharmacol. 2012;70:425-37.

36. Hynes NE, MacDonald G. ErbB receptors and signaling pathways in cancer. Curr Opin Cell Biol. 2009;21(2):177-84.

37. Chen Y, Mathy NW, Lu H. The role of VEGF in the diagnosis and treatment of malignant pleural effusion in patients with nonsmall cell lung cancer (Review). Mol Med Rep. 2018;17(6):8019-30.

38. Wang D, Donner DB, Warren RS. Homeostatic modulation of cell surface KDR and Flt1 expression and expression of the vascular endothelial cell growth factor (VEGF) receptor mRNAs by VEGF. J Biol Chem. 2000;275(21):15905-11.

39. YosefYarden, Sliwkowski MX. UNTANGLING THE ErbB SIGNALLING NETWORK. Nat Rev Mol Cell Biol. 2001;2:127-37.

40. Martini M, De Santis MC, Braccini L, Gulluni F, Hirsch E. PI3K/AKT signaling pathway and cancer: an updated review. Ann Med. 2014;46(6):372-83.

41. Wang BJ, Zheng WL, Feng NN, Wang T, Zou H, Gu JH, Yuan Y, Liu XZ, Liu ZP, Bian JC. The Effects of Autophagy and PI3K/AKT/m-TOR Signaling Pathway on the Cell-Cycle Arrest of Rats Primary Sertoli Cells Induced by Zearalenone. Toxins (Basel) 2018;10(10).

42. Lee HJ, Venkatarame Gowda Saralamma V, Kim SM, Ha SE, Raha S, Lee WS, Kim EH, Lee SJ, Heo JD, Kim GS. Pectolinarigenin Induced Cell Cycle Arrest, Autophagy, and Apoptosis in Gastric Cancer Cell via PI3K/AKT/mTOR Signaling Pathway. Nutrients 2018;10(8).

43. Mao Z, Shen X, Dong P, Liu G, Pan S, Sun X, Hu H, Pan L, Huang J. Fucosterol exerts antiproliferative effects on human lung cancer cells by inducing apoptosis, cell cycle arrest and targeting of Raf/MEK/ERK signalling pathway. Phytomedicine. 2019;61:152809.

44. Yang JC-H, Wu Y-L, Schuler M, Sebastian M, Popat S, Yamamoto N, Zhou C, Hu C-P, O'Byrne K, Feng J, Lu S, Huang Y, Geater SL, Lee KY, Tsai C-M, Gorbunova V, Hirsh V, Bennouna J, Orlov S, Mok T, Boyer M, Su W-C, Lee KH, Kato T, Massey D, Shahidi M, Zazulina V, Sequist LV. Afatinib Versus Cisplatin-Based Chemotherapy for EGFR Mutation-Positive Lung Adenocarcinoma (LUX-Lung 3 and 
LUX-Lung 6): Analysis of Overall Survival Data From Two Randomised, Phase 3. Trials Lancet Oncol. 2015;16:141-51.

45. Reck M, Taylor F, Penrod JR, DeRosa M, Morrissey L, Dastani H, Orsini L, Gralla RJ. Impact of Nivolumab versus Docetaxel on Health-Related Quality of Life and Symptoms in Patients with Advanced Squamous Non-Small Cell Lung Cancer: Results from the CheckMate 017 Study. J Thorac Oncol. 2018;13(2):194-204.

46. Rosell R, Carcereny E, Gervais R, Vergnenegre A, Massuti B, Felip E, Palmero R, Garcia-Gomez R, Pallares C, Sanchez JM, Porta R, Cobo M, Garrido P, Longo F, Moran T, Insa A, De Marinis F, Corre R, Bover I, Illiano A, Dansin E, de Castro J, Milella M, Reguart N, Altavilla G, Jimenez U, Provencio M, Moreno MA, Terrasa J, Muñoz-Langa J, Valdivia J, Isla D, Domine M, Molinier O, Mazieres J, Baize N, Garcia-Campelo R, Robinet G, Rodriguez-Abreu D, Lopez-Vivanco G, Gebbia V, Ferrera-Delgado L, Bombaron P, Bernabe R, Bearz A, Artal A, Cortesi E, Rolfo C, Sanchez-Ronco M, Drozdowskyj A, Queralt C, de Aguirre I, Ramirez JL, Sanchez JJ, Molina MA, Taron M, Paz-Ares L. Erlotinib versus standard chemotherapy as first-line treatment for European patients with advanced EGFR mutationpositive non-small-cell lung cancer (EURTAC): a multicentre, open-label, randomised phase 3 trial. The Lancet Oncology. 2012;13(3):239-46.

47. Solomon BJ, Mok T, Kim DW, Wu YL, Nakagawa K, Mekhail T, Felip E, Cappuzzo F, Paolini J, Usari T, lyer S, Reisman A, Wilner KD, Tursi J, Blackhall F, Investigators P. First-line crizotinib versus chemotherapy in ALK-positive lung cancer. N Engl J Med. 2014;371(23):2167-77.

48. Hida T, Nokihara H, Kondo M, Kim YH, Azuma K, Seto T, Takiguchi Y, Nishio M, Yoshioka H, Imamura F, Hotta K, Watanabe S, Goto K, Satouchi M, Kozuki T, Shukuya T, Nakagawa K, Mitsudomi T, Yamamoto N, Asakawa T, Asabe R, Tanaka T, Tamura T. Alectinib versus crizotinib in patients with ALK -positive non-small-cell lung cancer (J-ALEX): an open-label, randomised phase 3 trial. The Lancet. 2017;390(10089):29-39.

49. Brahmer JR, Rodríguez-Abreu D, Robinson AG, Hui R, Csőszi T, Fülöp A, Gottfried M, Peled N, Tafreshi A, Cuffe S, O'Brien M, Rao S, Hotta K, Zhang J, Lubiniecki GM, Deitz AC, Rangwala R, Reck M. Healthrelated quality-of-life results for pembrolizumab versus chemotherapy in advanced, PD-L1-positive NSCLC (KEYNOTE-024): a multicentre, international, randomised, open-label phase 3 trial. Lancet Oncol. 2017;18:1600-9.

50. Li XJ, Jiang ZZ, Zhang LY. Triptolide: progress on research in pharmacodynamics and toxicology. J Ethnopharmacol. 2014;155(1):67-79.

51. Zhou W, Wang Y, Lu A, Zhang G. Systems Pharmacology in Small Molecular Drug Discovery. Int J Mol Sci. 2016;17(2):246.

52. Tari AM, Lopez-Berestein G. GRB2 a pivotal protein in signal transduction. Semin Oncol. 2001;28:142-7.

53. Giubellino A Jr, Bottaro TRB. DP. Grb2 signaling in cell motility and cancer. Expert Opin Ther Targets. 2008;12:1021-33. 
54. da Cunha Santos G, Shepherd FA, Tsao MS. EGFR mutations and lung cancer. Annu Rev Pathol. 2011;6:49-69.

55. Kozer N, Barua D, Henderson C, Nice EC, Burgess AW, Hlavacek WS, Clayton AH. Recruitment of the adaptor protein Grb2 to EGFR tetramers. Biochemistry. 2014;53(16):2594-604.

56. Del Piccolo N, Hristova K. Quantifying the Interaction between EGFR Dimers and Grb2 in Live Cells. Biophys J. 2017;113(6):1353-64.

57. Ahmed Z, Timsah Z, Suen KM, Cook NP, Lee GRt, Lin CC, Gagea M, Marti AA, Ladbury JE. Grb2 monomer-dimer equilibrium determines normal versus oncogenic function. Nat Commun. 2015;6:7354.

58. Dharmawardana PG, Peruzzi B, Giubellino A Jr, Bottaro TRB. DP. Molecular targeting of growth factor receptor-bound 2 (Grb2) as an anti-cancer strategy. Anticancer Drugs. 2006;17:13-20.

59. Sanches K, Dias RVR, da Silva PH, Fossey MA, Caruso IP, de Souza FP, de Oliveira LC, de Melo FA. Grb2 dimer interacts with Coumarin through SH2 domains: A combined experimental and molecular modeling study. Heliyon. 2019;5(11):e02869.

60. Roberts PJ, Der CJ. Targeting the Raf-MEK-ERK mitogen-activated protein kinase cascade for the treatment of cancer. Oncogene. 2007;26(22):3291-310.

\section{Figures}

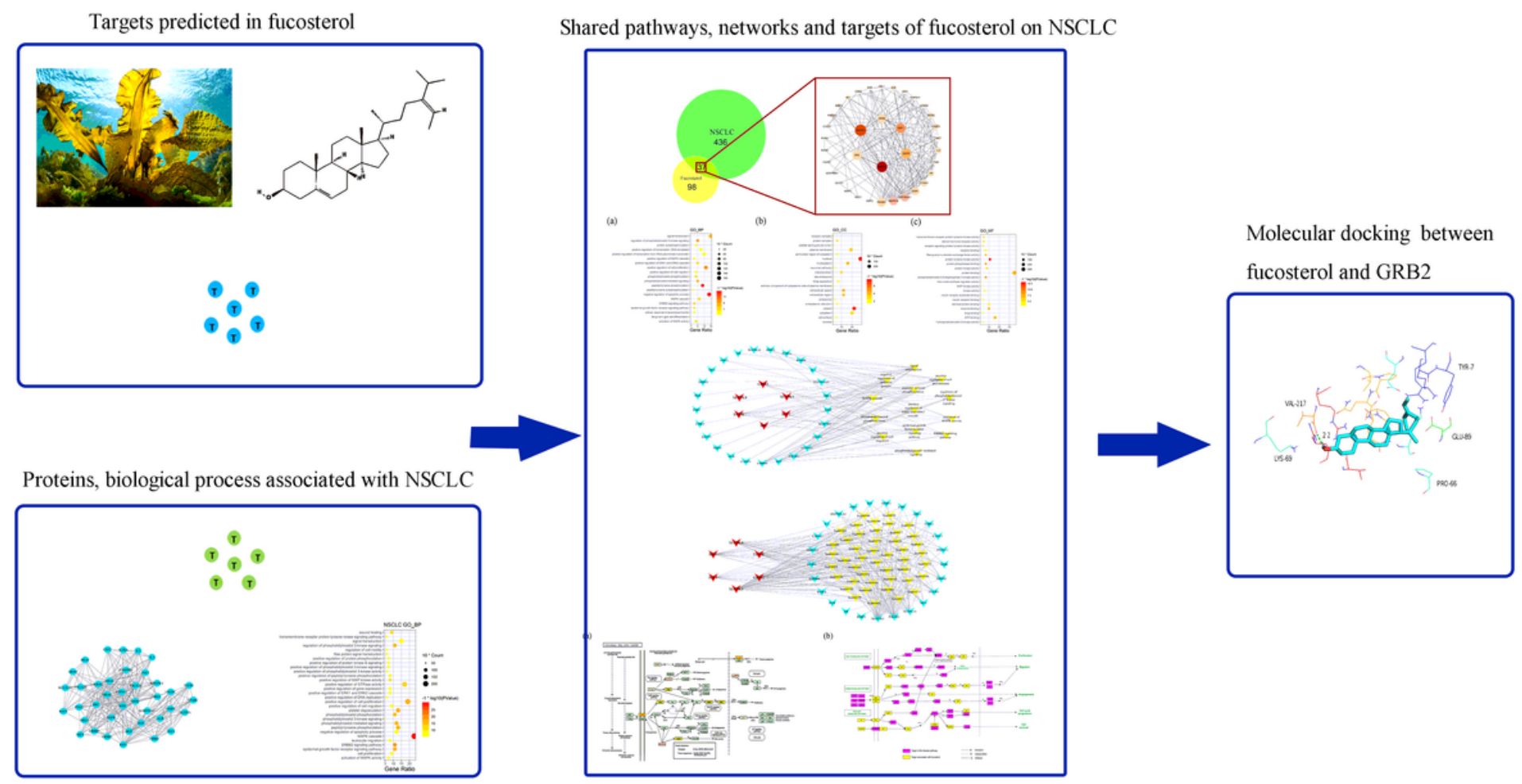

Figure 1

Diagram of the study design. 


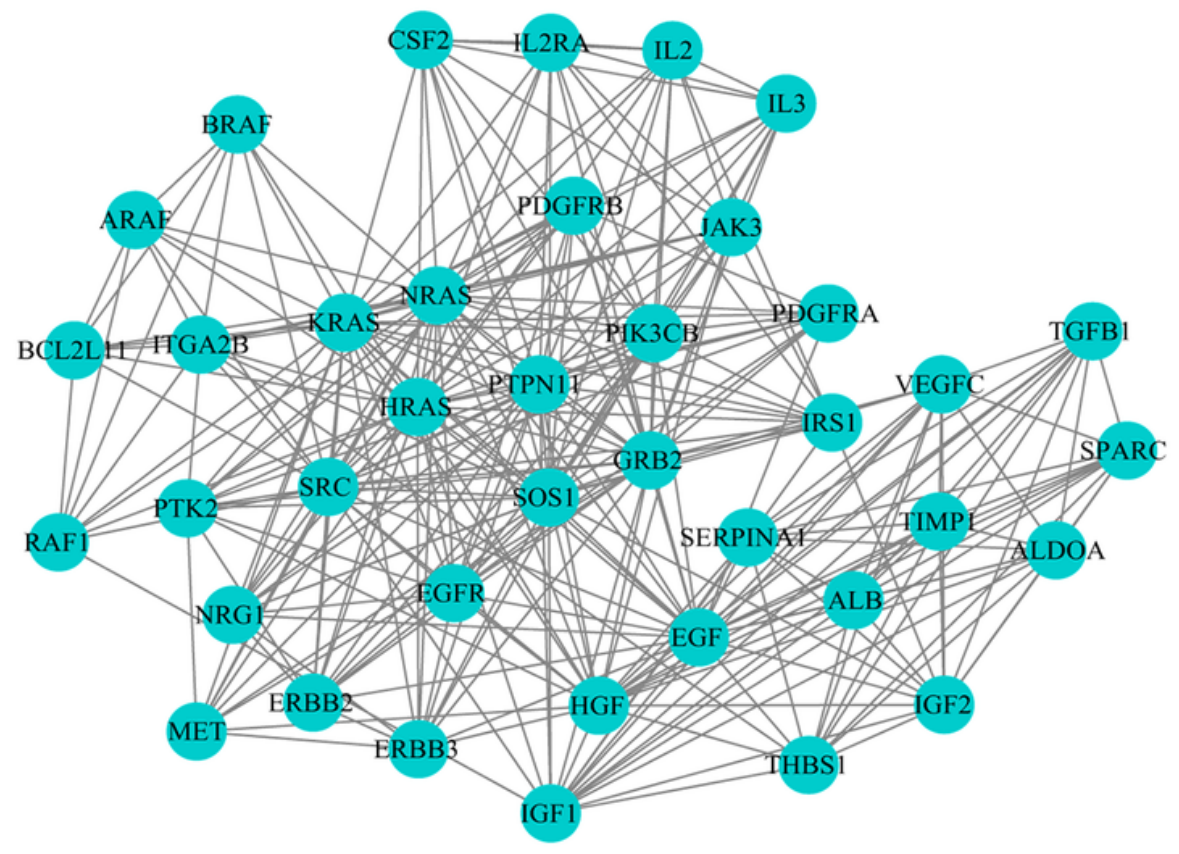

Figure 2

Cluster 1 for NSCLC network 
NSCLC GO_BP

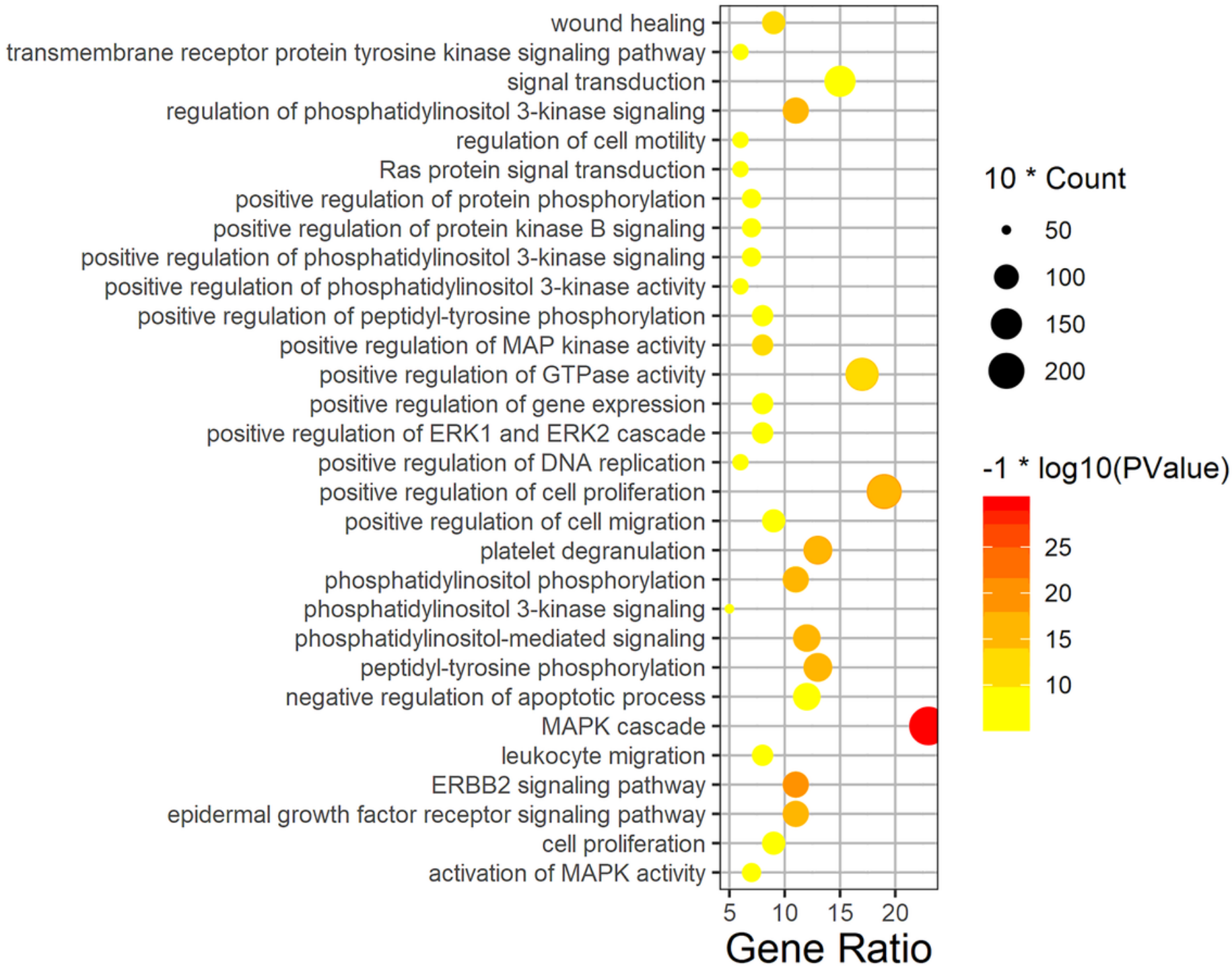

\section{Figure 3}

Biological process bubble diagram of cluster 1. The color scales indicate different thresholds of adjusted p-values, and the sizes of the dots represent the gene count of each term. 


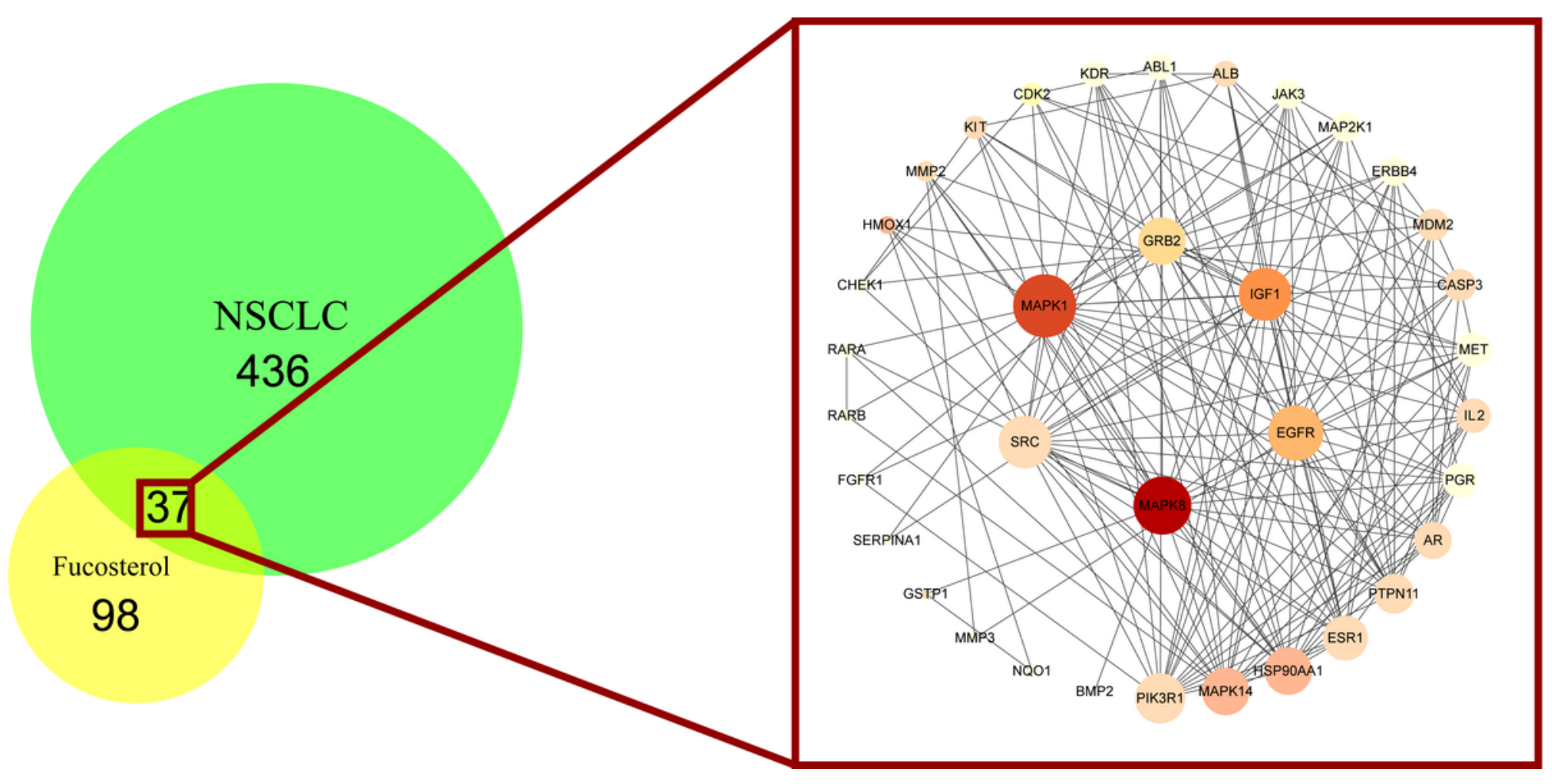

Figure 4

The related targets of NSCLC and predicted targets of fucosterol were screen and combined for constructing a PPI network.

A

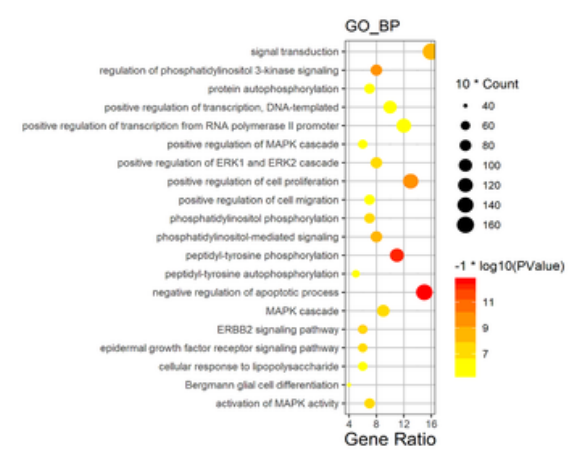

B

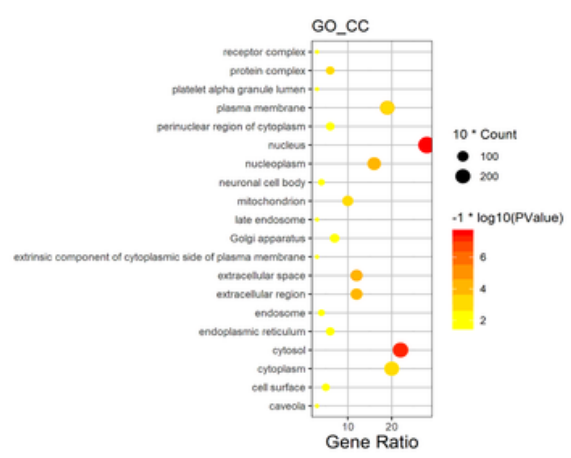

$\mathrm{C}$

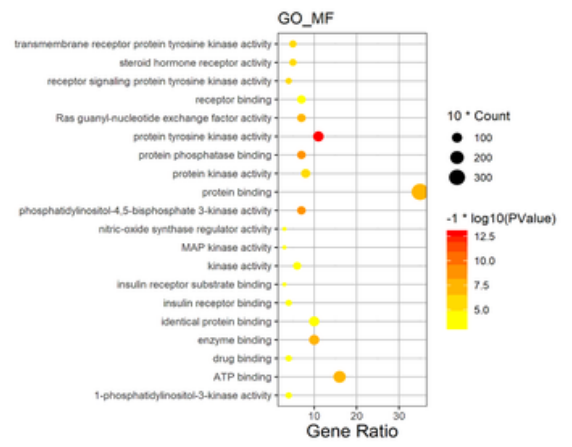

\section{Figure 5}

GO analysis of candidate targets. GO enrichment analysis identified genes involved in (A)indicate different thresholds of adjusted p-values, and the sizes of the dots represent the gene count of each term. 


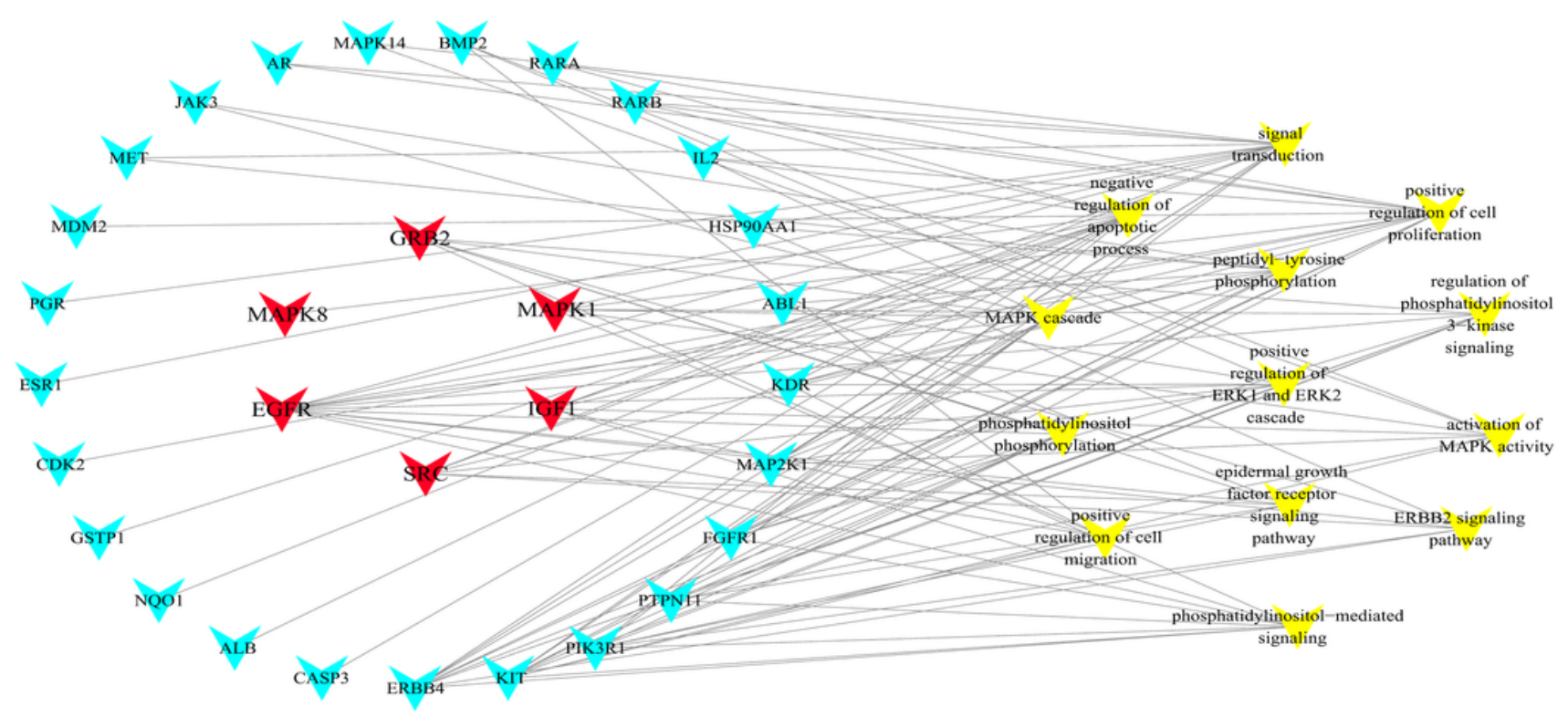

\section{Figure 6}

Important biological processes and candidate targets crosstalk in the treatment of NSCLC with fucosterol. Node in red is the hub gene, node in blue is targets in fucosterol, and yellow is the specific biological process.

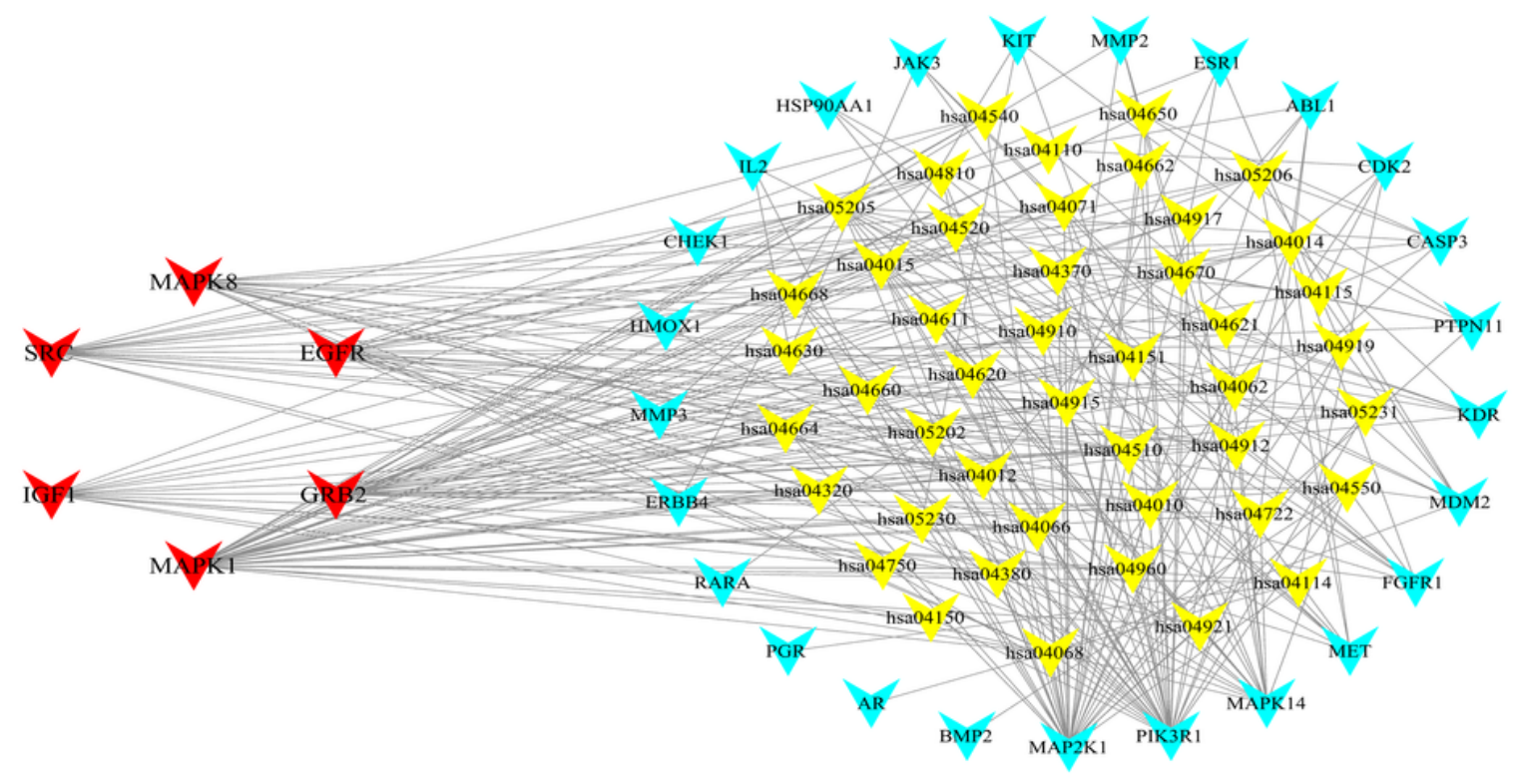

\section{Figure 7}

Target-pathway network. The T-P network is built by the candidate targets and a pathway if the pathway is lighted at the target. Yellow nodes represent signaling pathway from enrichment analysis. Blue nodes represent the candidate targets in fucosterol. Red nodes represent the hub genes screened by PPI network. 
A

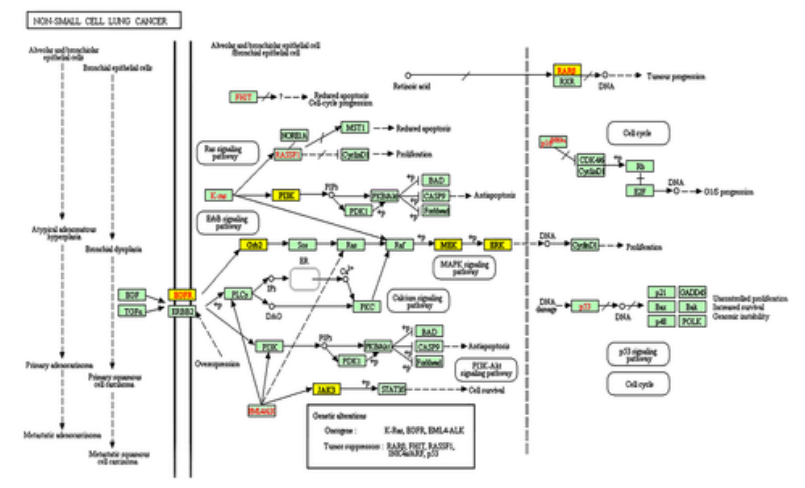

B

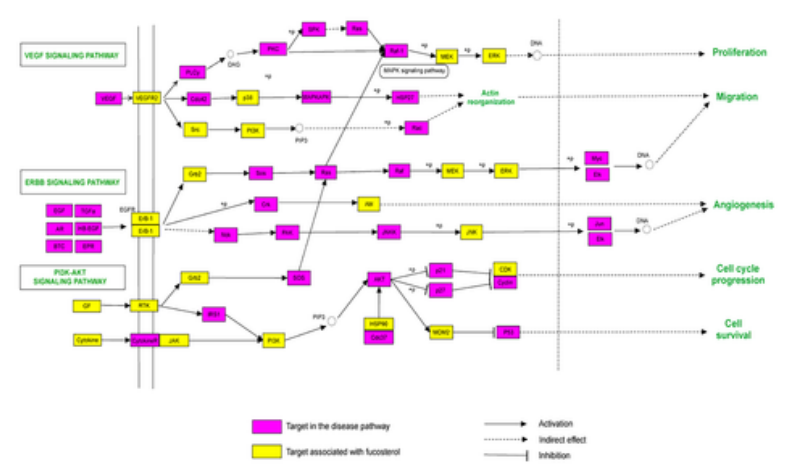

Figure 8

The integrated pathways map of fucosterol in the treatment of NSCLC include (A) the non-small cell lung cancer pathway, marked in yellow as the functional targets of fucosterol, and (B) the key signal transduction pathways.

\section{A}

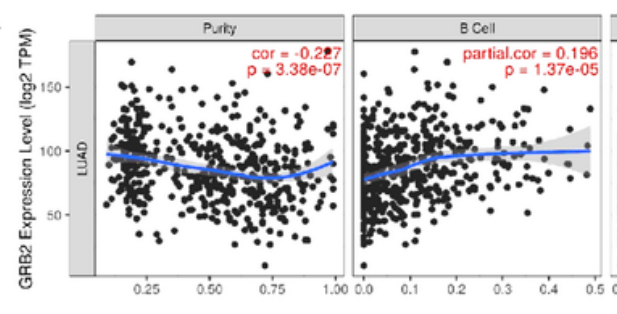

B

\begin{tabular}{|c|c|c|}
\hline variable & partial.cor & $p$ \\
\hline Purity & -0.22708 & $3.38 \mathrm{E}-07$ \\
\hline B Cell & 0.196239 & $1.37 \mathrm{E}-05$ \\
\hline CD8+ T Cell & 0.307506 & $3.99 \mathrm{E}-12$ \\
\hline CD4+ T Cell & 0.385729 & $1.28 \mathrm{E}-18$ \\
\hline Macrophage & 0.404903 & $1.47 \mathrm{E}-20$ \\
\hline Neutrophil & 0.541071 & $4.43 \mathrm{E}-38$ \\
\hline Dendritic Cell & 0.544328 & $5.45 \mathrm{E}-39$ \\
\hline
\end{tabular}
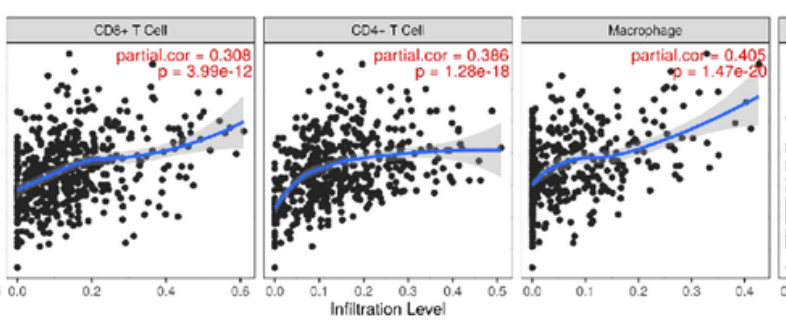
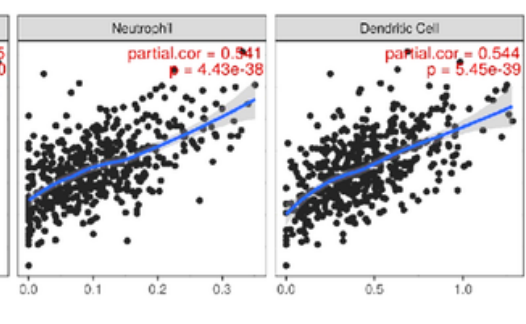

C

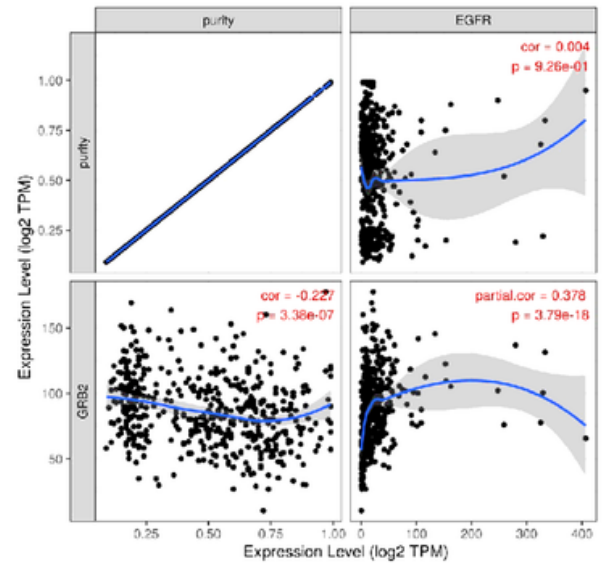

$\mathrm{D}$

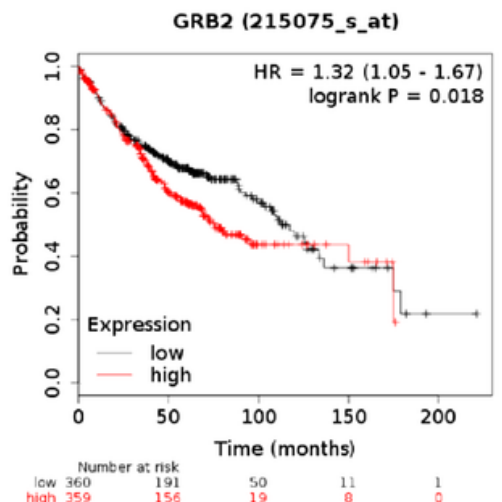

\section{Figure 9}

The expression of GRB2 and immune infiltrates in NSCLC. (A-B) Correlation of GRB2 expression with immune infiltration level in LUAD. GBR2 expression had significant positive correlations with infiltrating levels of CD4+T cells, CD8+T cells, B cells, neutrophils, macrophages and dendritic cells (C) Relationship between GRB2 and EGFR in LUAD. GRB2 expression showed a strong correlation with EGFR expression after adjusting tumor purity in LUAD. (D) Prognostic values of GRB2 ( $n=2437)$ in lung adenocarcinoma 
(OS in Kaplan-Meier plotter). Line in red with high expression while in black with low expression. Low expression of GRB2 was connected with better over survival.
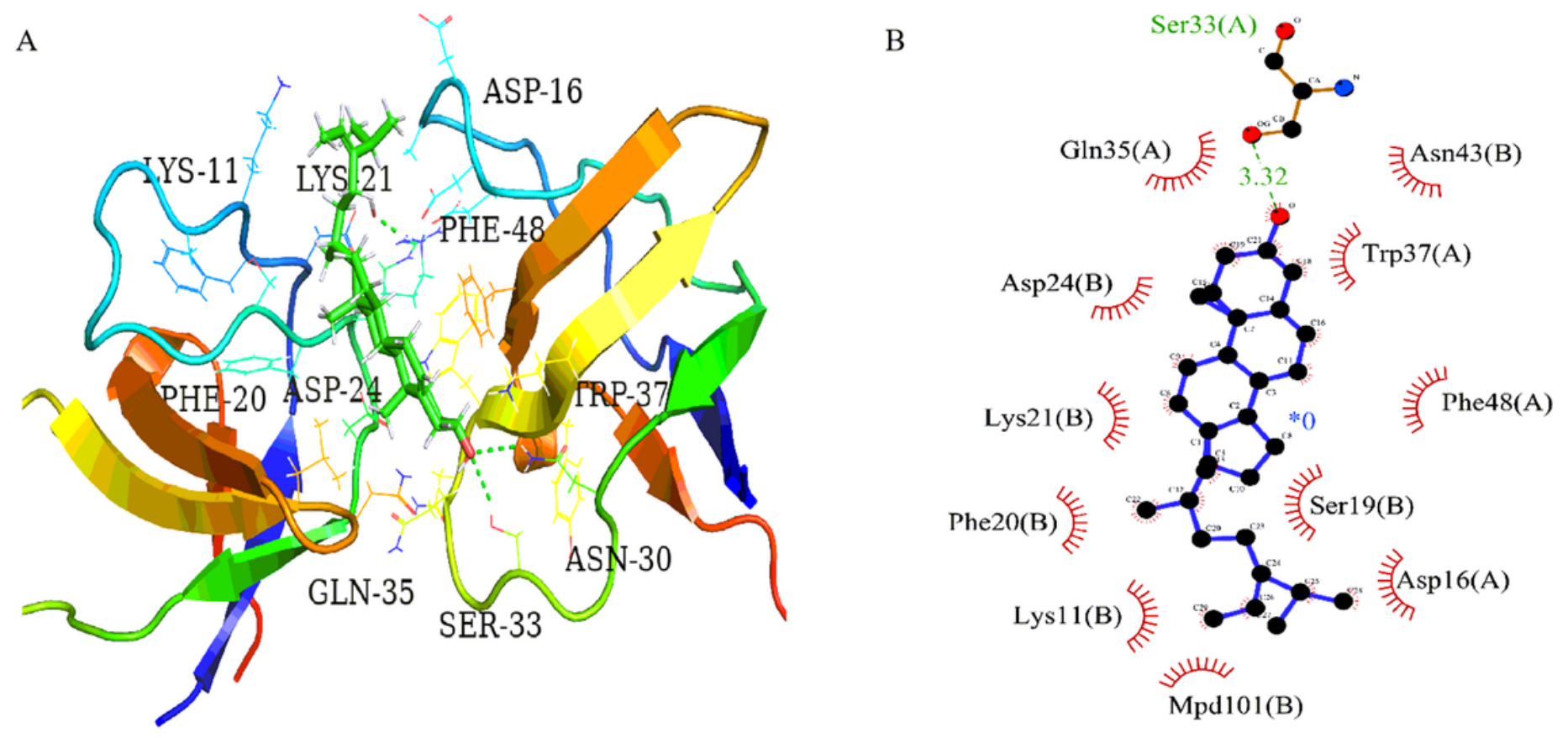

Figure 10

Simulation results of GRB2, with fucosterol. (A) The docking site of GRB2 and fucosterol. (B) Display of the interaction between GRB2 with fucosterol. 